\title{
Rapid evolution of Anguillicola crassus in Europe: species diagnostic traits are plastic and evolutionarily labile
}

\author{
Urszula Weclawski ${ }^{*}$, Emanuel G Heitlinger ${ }^{1}$, Tobias Baust ${ }^{2}$, Bernhard Klar $^{2}$, Trevor Petney $^{1}$, Yu-San Han ${ }^{3}$ \\ and Horst Taraschewski ${ }^{*}$
}

\begin{abstract}
Background: Since its introduction from Taiwan to Europe around 1980, Anguillicola crassus, a natural parasite of the Japanese eel (Anguilla japonica), has acquired the European eel (Anguilla anguilla) as a novel definitive host. In this host the nematode differs noticeably in its body mass and reproductive capacity from its Asian conspecifics. We conducted a common garden experiment under a reciprocal transplant design to investigate whether differences in species-diagnostic morphological traits exist between two European and one Asian population of $A$. crassus and if yes whether these have a genetically fixed component.

Results: We found that worms from Germany, Poland and Taiwan differ in the size and shape of their body, oesophagus and buccal capsule. These changes are induced by both phenotypic plasticity and genetic divergence: in the European eel, nematodes from Europe as well as from Taiwan responded plastically with larger body and oesophagus dimensions compared to infections in the Japanese eel. Interestingly, the oesophagus simultaneously shows a high degree of genetically based changes being largest in the Polish strain kept in A. anguilla. In addition, the size and shape of the buccal capsule has undergone a rapid evolutionary change. Polish nematodes evolved a genetically fixed larger buccal capsule than the German and Taiwanese populations. The German strain had the smallest buccal capsule.
\end{abstract}

Conclusions: This study provides evidence for the genetic divergence of morphological traits in $A$. crassus which evolved over a timescale of about 30 years. Within Europe and in the European eel host these alternations affect characters used as diagnostic markers for species differentiation. Thus we provide an explanation of the discrepancy between morphological and molecular features reported for the parasitic nematode featured here, demanding general caution in morphological diagnosis of parasites discovered in new hosts.

Keywords: Anguillicola crassus, Anguillicoloides, Introduction, Biological invasion, Host switch, Rapid evolution, Genetic divergence, Phenotypic plasticity, Evolutionary labile traits

\section{Background}

Anguillicola crassus, a natural swim bladder parasite of the Japanese eel (Anguilla japonica) [1], is one of the most successful aquatic parasitic aliens in the history of globalization. Within about 30 years of its introduction from Taiwan to Germany around 1980 this nematode has spread throughout the European continent and

\footnotetext{
* Correspondence: weclawski.urszula@googlemail.com; horst.taraschewski@kit.edu 'Department of Ecology and Parasitology, Zoological Institute, Karlsruhe Institute of Technology, Kornblumenstrasse 13, Karlsruhe, Germany Full list of author information is available at the end of the article
}

North Africa colonizing almost all populations of the European eel (Anguilla anguilla) [2,3].

Invasive pathogens and most prominently $A$. crassus have thus been proposed as an additional cause for the decline of European eel stocks, along with overfishing and habitat destruction [4].

The development of $A$. crassus requires copepod or ostracod intermediate hosts and a final host belonging to the genus Anguilla in the natural as well as the novel range [5]. After the ingestion of an infected intermediate or a paratenic host by an eel [6], the L3 larvae migrate 
through the intestinal wall and body cavity towards the swim bladder. In the swim bladder wall the L3 develop via the L4 stage to pre-adults that enter the swim bladder lumen. Sexually dimorphic adults eventually mate and L2 are released by females. These L2 reach the water via the eel's faeces and are ingested by an intermediate host in which they moult to the L3 stage [5].

Field studies in Europe and Asia have revealed that the worms infecting the European eel are much larger than their Taiwanese conspecifics in the Japanese eel [7]. In experiments with European parasites in A. anguilla and A. japonica infectivity, body mass, weight gain and reproductive output were significantly higher in the European eel than in the natural host, while larval mortality was lower in the colonized host [8].

Similarly, the American eel is more heavily affected by A. crassus than the Japanese eel [9].

Recently, we demonstrated rapid genetic divergence of the introduced European parasite population compared to conspecifics from Taiwan in terms of infectivity and developmental dynamics, using a reciprocal transplant experiment under common garden conditions [10]. In this paper, we report on the morphological traits of parasites from these studies.

The oesophagus (i.e. pharynx) and the buccal capsule are involved in the ingestion of food, in adult A. crassus, namely blood from host capillaries [11]. The oesophagus is a muscular structure that likely creates a vacuum while sucking blood into the worm's gut. The buccal capsule is a sclerotinized structure that bears the teeth and acts as an abutment to the applied pressure $[12,13]$.

The different feeding behaviour of larger nematode groups (esp. in the Spriurina and the whole of the Rhabditida) is reflected by structural variability of the oesophagus and the buccal capsule. The taxonomy of nematodes thus traditionally relies on these characters [14].

Based on these features A. crassus, Anguillicola novaezelandiae and Anguillicola papernai can be differentiated (in addition to differences in natural host usage and distributional range). In contrast, Anguillicola australiensis showed an additional specific character. Its anterior end is inflated, forming a bulb around the mouth opening [15]. Later, the subgenus Anguillicoloides, to which all 4 species belonged, was transferred to the status of a genus, while the genus Anguillicola retained only one species, Anguillicola globiceps [16]. According to molecular evidence, however, the new genus and the previous subgenus are paraphyletic and the original generic grouping is more appropriate [17]. For this reason the generic name Anguillicola is used in this paper. In the present study we investigated whether taxonomically important morphological characters are affected by rapid evolution following the colonization of a novel host in a recipient area.

\section{Results}

In the European eel 1,136 adult worms were chosen for morphological investigations: 424 (45.4\% female, $54.6 \%$ male) worms belonging to the German, $387(41.4 \%$ female, $58.6 \%$ male) to the Polish and 325 (30\% female, $70 \%$ male) to the Taiwanese worm population. In the Japanese eels from 430 (37.1\% female, 62.9\% male) adult worms that were chosen for morphological studies 179 (44.4\% female, $55.6 \%$ male) worms belonged to the German population, 142 ( $47.4 \%$ female, $52.6 \%$ male) to Polish and 111 (43.5\% female, $56.5 \%$ male) to the Taiwanese population.

\section{Body}

In the Japanese eel, the worms were generally smaller for both body dimensions (width and length) and also grew less quickly than in the European eel (Figure 1, Additional file 1: Table S1, Additional file 2: Table S2, Additional file 3: Figure S1). They also had a higher length/width ratio (Table 1). Further, since the (estimated) coefficient for dpi is almost precisely the negative of the coefficient for the interaction between Japanese eel and dpi, the coefficient for dpi for the Japanese eel (which is the sum of both values) is roughly zero (Table 1). This means that the shape of the worms in the Japanese eel did not change significantly over time.

Under the same host conditions no differences between the 3 nematode strains were found: in both eel species the parasite populations did not differ from one another with respect to length or width of their body (Additional file 1: Table S1, Additional file 2: Table S2; Figure 1, Additional file 3: Figure S1).

The only significant difference found was a smaller length/width ratio for the Taiwanese population infecting the Japanese eel, indicating a shorter body of Taiwanese worms in this host species compared to both European populations (Table 1).

\section{Oesophagus}

In both eel species the Polish $A$. crassus population had a wider but shorter oesophagus than did the German and Taiwanese strains (Table 2, Additional file 4: Table S3, Additional file 5: Table S4, Figure 2, Additional file 6: Figure S2). There were no differences in length, width and aspect ratio of the oesophagus between the German and Taiwanese strains. The larger dimensions and shorter shape of the oesophagus of the Polish parasite population are apparently genetically fixed.

The oesophagus of the worms in the Japanese eel was thinner (Figure 2, Additional file 5: Table S4, Additional file 6: Figure S2) and grew less quickly (Additional file 4: Table S3, Additional file 5: Table S4) than that of worms in European eels. In addition, there was a non-significant trend $(p=0.097)$ towards a shorter oesophagus in worms 


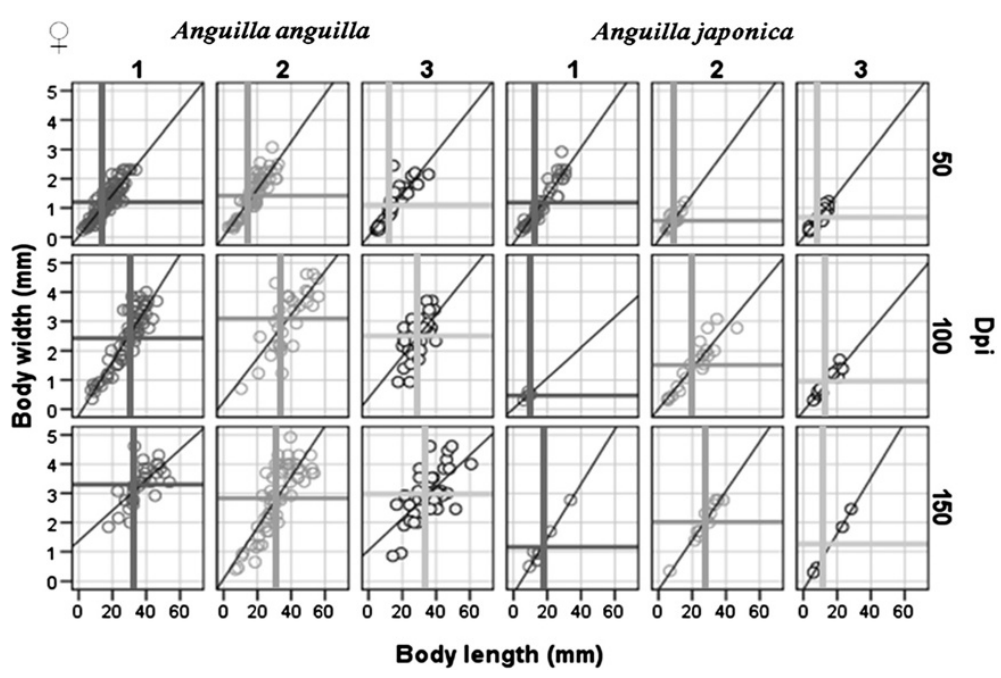

Figure 1 Body dimensions of female adults of Anguillicola crassus in Anguilla anguilla and A. japonica. Body length and width of female adults of Anguillicola crassus in Anguilla anguilla and A. japonica with the arithmetic mean values (horizontal and vertical lines) and the linear regression lines. 1 - German parasite population, 2 - Polish parasite population, 3 - Taiwanese parasite population. Dpi - days post infection. For same visualization for male worms see: Additional file 3: Figure S1.

from this host species. In the Japanese eel the oesophagus had a higher length/width ratio (Table 2).

\section{Buccal capsule}

Neither of the dimensions (width and length) of the worms' buccal capsule differed between specimens harboured in the different host species (Figure 3, Additional file 7: Table S5, Additional file 8: Table S6, Additional file 9: Figure S3). Only male worms had a slightly but significantly shorter buccal capsule in the Japanese eel (Table 3).

In both eel species the Polish nematode strain had the biggest buccal capsule (longer and wider) than that of the German and Taiwanese strains. The buccal capsule of the Taiwanese worms showed a trend $(\mathrm{p}=0.08)$ towards wider shape than that of the German conspecifics but it was significantly longer (Figure 3, Additional file 7: Table S5, Additional file 8: Table S6, Additional file 9: Figure S3).

The shape of the buccal capsule did not differ significantly between the Polish and Taiwanese worms, but both populations had a longer buccal capsule than the German specimens (Table 3). Thus, again, the two European populations differed from one another.

\section{Discussion}

A. crassus has a historically well documented invasion time line. The first published reports of its presence in Europe date from the early 1980s [18,19]. It had therefore been in Europe for about 30 years at the time our experiments were carried out.

Table 1 Minimal adequate mixed-effects linear model for body ratio of Anguillicola crassus: reference group: German parasite population in the European eel

\begin{tabular}{lllll}
\hline Explanatory variables and interactions & Estimate & SD & t-value & $\mathbf{p}$-value \\
\hline (Intercept) & 13.993017 & 0.344908 & 40.570 & $\mathbf{0 . 0 0 0 0}$ \\
Japanese eel & 2.864821 & 0.597873 & 4.792 & $\mathbf{0 . 0 0 0 0}$ \\
Polish parasite population & -0.351104 & 0.384348 & -0.914 & 0.3618 \\
Taiwanese parasite population & 0.415774 & 0.407112 & 1.021 & -3.816 \\
Dpi & -0.017952 & 0.004705 & 8.551 & $\mathbf{0 . 0 0 0 2}$ \\
Male & 2.515979 & 0.294228 & -0.783 & $\mathbf{0 . 0 0 0 0}$ \\
Japanese eel*Polish parasite population & -0.565012 & 0.721843 & -3.826 & 0.4345 \\
Japanese eel*Taiwanese parasite population & -2.825598 & 0.738580 & 0.355 & $\mathbf{0 . 0 0 0 2}$ \\
Japanese eel*Dpi & 0.017957 & 0.007626 & $\mathbf{0 . 0 1 9 3}$ \\
Dpi*Male & 0.011858 & 0.004458 & $\mathbf{2 . 6 6 0}$ & $\mathbf{0 . 0 0 7 9}$ \\
Japanese eel*Male & -1.012030 & 0.422709 & $\mathbf{0 . 0 1 6 8}$ \\
\hline
\end{tabular}

Significant effects are in bold. 
Table 2 Minimal adequate mixed-effects linear model for oesophagus ratio of Anguillicola crassus: reference group: German parasite population in the European eel

\begin{tabular}{lllll}
\hline Explanatory variables and interactions & Estimate & SD & t-value & p-value \\
\hline (Intercept) & 3.317222 & 0.032135 & 103.229 & $\mathbf{0 . 0 0 0 0}$ \\
Japanese eel & 0.354854 & 0.043646 & $\mathbf{0 . 1 3 0}$ & $\mathbf{0 . 0 0 0 0}$ \\
Polish parasite population & -0.152373 & 0.033900 & -4.495 & $\mathbf{0 . 0 0 0 0}$ \\
Taiwanese parasite population & -0.030428 & 0.035232 & -0.864 & $\mathbf{0 . 0 0 0 0}$ \\
Dpi & -0.004029 & 0.000415 & -9.701 & $\mathbf{0 . 0 2 6 8}$ \\
Male & -0.048802 & 0.022015 & -2.217 & $\mathbf{0 . 0 0 3 7}$ \\
Japanese eel*Dpi & 0.002353 & 0.000802 & & 2.933 \\
\hline
\end{tabular}

Significant effects are in bold.

Using a cross-infection experiment with both Asian and European hosts and parasites we postulate divergence linked to the origin of the parasite and not to the species of the experimental host to be genetically fixed. We show that the morphology of the body, oesophagus and buccal capsule of $A$. crassus show a mixture of both plastic and genetically fixed differences.

We report a larger body mass and size of worms raised in the European eel compared to the Japanese eel. A similar finding with $A$. anguilla and A. japonica infected with A. crassus from Germany has previously been documented [8]. We conclude that this feature of the worm is based only on phenotypic plasticity since we show that it is linked only to the species of experimental host and not to the origin of the parasite. For A. japonica we assume that the worms are subjected to a strong concomitant immunity limiting the weight gain of the parasite. This hypothesis is supported by the lower prevalence and intensities of $A$. crassus in its natural host [7], by a stronger and more rapid production of antibodies directed against the parasite $[20,21]$ and by the ability of the Japanese eel to encapsulate and eliminate visceral larvae of $A$. crassus [22].

Concerning the size and shape of the oesophagus, phenotypic modification also seems to be present. It is not surprising that the development and growth of this muscular structure is influenced by the same factors as the overall body dimensions as shown, for example, in Halicephalobus cf. gingivalis [23].

However, we could not detect any influence of the host on size or shape of the buccal capsule, and we thus conclude a lack of environmental influence on that structure. The size and shape of this sclerotinized structure seems to be genetically determined and fully independent of the worms overall size. Growth of nematodes and other organisms keeping sclerotinized organs in constant dimensions is a known phenomenon, and these features are thus traditionally regarded as suitable for morphological taxonomy $[24,25]$.

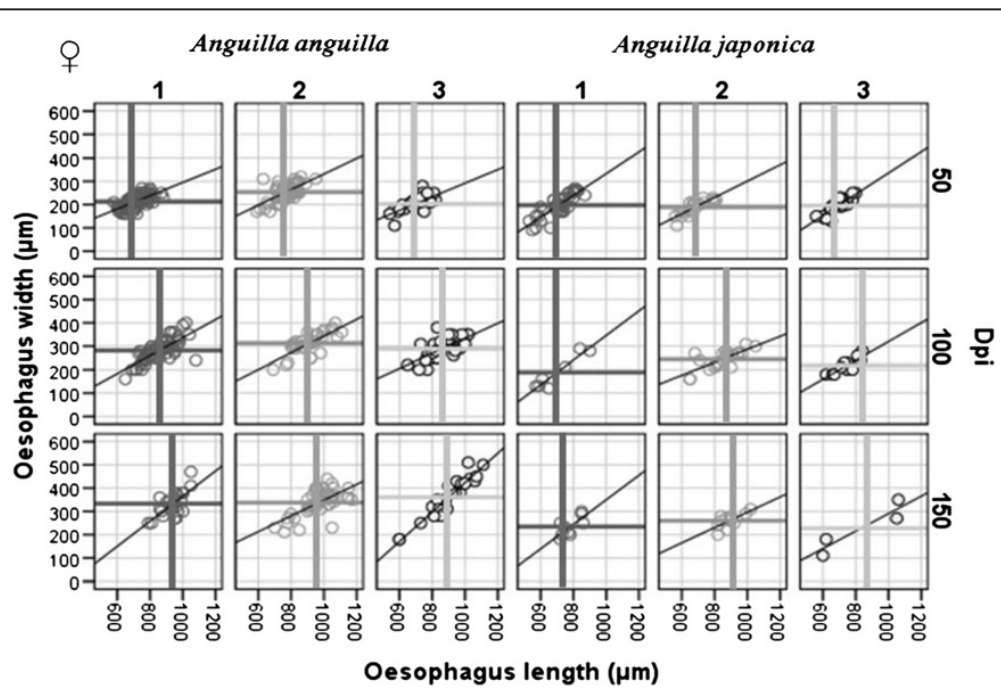

Figure 2 Oesophagus dimensions of female adults of Anguillicola crassus in Anguilla anguilla and A. japonica. Oesophagus length and body width of female adults of Anguillicola crassus in Anguilla anguilla and A. japonica with the arithmetic mean values (horizontal and vertical lines) and the linear regression lines. 1 - German parasite population, 2 - Polish parasite population, 3 - Taiwanese parasite population. Dpi - days post infection. For the same visualization for male worms see: Additional file 5: Figure S2. 


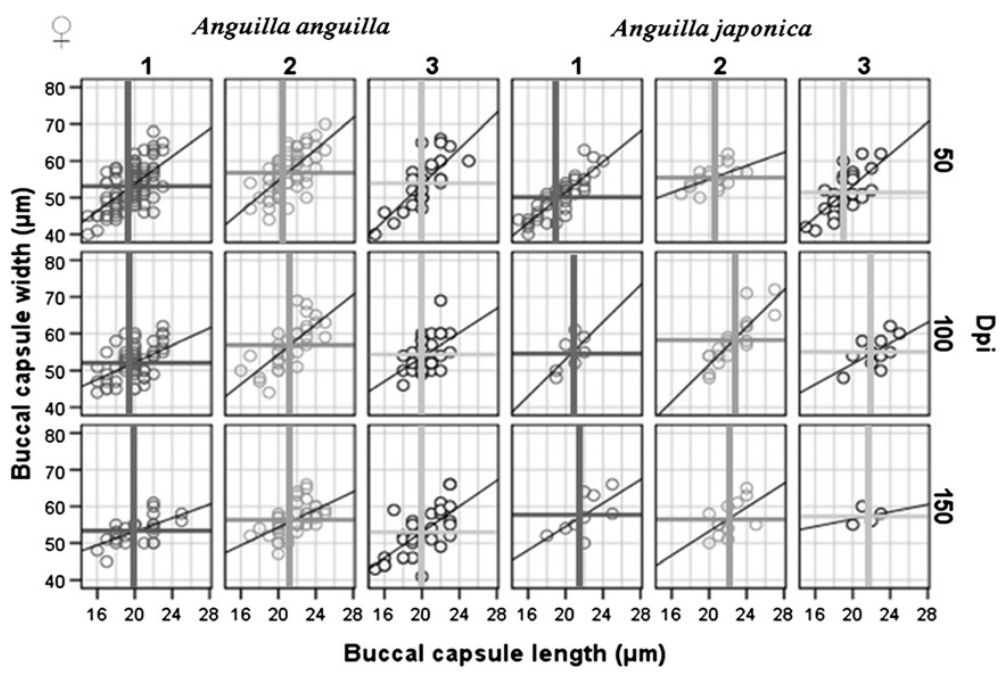

Figure 3 Buccal capsule dimensions of female adults of Anguillicola crassus in Anguilla anguilla and A. japonica. Buccal capsule length and width of female adults of Anguillicola crassus in Anguilla anguilla and A. japonica with the arithmetic mean values (horizontal and vertical lines) and the linear regression lines. 1 - German parasite population, 2 - Polish parasite population, 3 - Taiwanese parasite population. Dpi - days post infection. For the same visualization for male worms see: Additional file 9: Figure S3.

Coming to the question of the most likely mode of the observed rapid evolution, the shape and size of the oesophagus and the buccal capsule of the worms from a German river directly linked to the place of original introduction [18] resemble the traits of the conspecifics from the donor area in Taiwan. Only a Polish strain of the parasite displayed rapid divergence of morphological features, as reflected by an enlargement of the buccal cavity and the oesophagus. Furthermore, transplantation experiments indicate that morphological changes in the Polish strain genetically fixed and intrinsic to the worms than a result of the host environment.

The host-induced sources of selective pressure are the same between Poland and Germany, but differ between European and Asian locations. This is especially true in the eel, a (nearly) panmictic species due to its spawning behaviour [26,27], excluding the possibility of local hostparasite adaptation. However, A. crassus seems to have colonized Poland via the brackish water of the Baltic
$[28,29]$. Our observations could be explained either via a bottleneck and genetic drift within the colonized eastern areas or by selective pressure exerted by the abiotic environment [30]. It appears that the rapid evolution of morphological traits in the parasite does not have to be directional as an adaptation to the host.

Indeed a molecular genetic survey using microsatellite markers found that allelic diversity of European populations reflected a moderate bottleneck associated with the introduction of the parasite into a novel area followed successive moderate loss of diversity during the southward expansions of its populations [30]. This argues for drift as an explanation of our findings.

It was recently shown that genetically fixed changes in infectivity and developmental traits separate European A. crassus from their Taiwanese conspecifics [10]. The selective pressure of the novel host (European eel), not the genetic drif, was thus considered to have modified the developmental features in the European strains of A. crassus.

Table 3 Minimal adequate mixed-effects linear model for buccal capsule ratio of Anguillicola crassus: reference group: German parasite population in the European eel

\begin{tabular}{lllll}
\hline Explanatory variables and interactions & Estimate & SD & t-value & p-value \\
\hline (Intercept) & 0.375781 & 0.002190 & 171.579 & $\mathbf{0 . 0 0 0 0}$ \\
Japanese eel & 0.009065 & 0.003123 & 2.902 & $\mathbf{0 . 0 0 4 0}$ \\
Polish parasite population & -0.004939 & 0.002317 & -2.131 & $\mathbf{0 . 0 3 4 0}$ \\
Taiwanese parasite population & -0.005019 & 0.002402 & -2.089 & $\mathbf{0 . 0 3 7 7}$ \\
Dpi & 0.000078 & 0.000024 & 3.214 & $\mathbf{0 . 0 0 1 5}$ \\
Male & 0.015202 & 0.002018 & $\mathbf{7 . 5 3 4}$ & $\mathbf{0 . 0 0 0 0}$ \\
Japanese eel*Male & -0.012043 & 0.003956 & -3.044 & $\mathbf{0 . 0 0 2 4}$
\end{tabular}

Significant effects are in bold. 
We show in the present publication that the mode (neutral or directional) of rapid evolution may differ for different traits in the same species. The differentiation between $A$. crassus, $A$. novaezelandiae and $A$. papernai for example is based mainly on features of the buccal capsule and oesophagus [5]. Our findings thus provide a possible explanation for the incongruence between morphological and molecular phylogeny [17] in the special case of the genus Anguillicola. If a diagnostic trait can repeatedly undergo rapid evolutionary change in one lineage but not in the other, species may be grouped wrongly in higher order taxa, such as (sub-) genera [31]. Our findings might point to an explanation for the common incongruence between phylogeny and morphological characteristics: Rapid evolution of a phenotypically stable character.

In addition, our results indicate that it is not well advised to use morphology alone for species discrimination and higher order systematics in nematodes and other taxonomic groups with limited morphological differentiation. Even if the morphological characters used do not vary in different environments (are phenotypically stable), the same characters might be evolutionarily labile potentially creating uninformative patterns of similarity. Furthermore, parasite evolution does not necessarily have to be directional, leading to host adaptation, but selection exerted by the abiotic environment or by neutral evolution and genetic drift can lead to divergence in ecological time.

\section{Conclusions}

A reciprocal transplant experiment under commongarden conditions allowed us to disentangle phenotypic modification from genetically fixed divergence of morphological traits in $A$. crassus. The nematode is larger in the recently acquired European host $A$. anguilla compared to the original Asian host $A$. japonica. Overall body dimensions seem only plastically modified and size differences showed no genetically fixed component.

The oesophagus was also affected by this environmentally induced plasticity. This trait, however, also showed genetically fixed differences between European populations of $A$. crassus. The sclerotinized structure of the buccal capsule, on the other hand is not modified by the host environment, but has genetically diverged between parasite populations within Europe.

We conclude that evolutionary change in characters important for morphological taxonomy has occurred in A. crassus in its novel European range. Moreover, we generalize our findings to suggest that traits which are normally phenotypically stable in helminths can be evolutionarily labile on an ecological time scale and are thus likely to introduce artefacts of taxonomic relevance. Species with limited morphological differentiation thus require the additional use of molecular methods for species differentiation, taxonomy and systematics. The molecular genetic architecture characterized by the traits discussed here should enable a broad characterisation of genome wide differences between the different $A$. crassus populations [32]. Our findings show also that this invasive species was able to change at the evolutionary level in ecological time, which is probably an important component of the dispersal success of introduced taxa.

\section{Methods}

\section{Experimental design}

We conducted a series of experiments infecting $A$. japonica and $A$. anguilla with $A$. crassus originating from Germany, Poland and Taiwan, as described in [10].

Briefly, L2 larvae were collected from wild eels from the Rhine River near Karlsruhe in the southwest of Germany, the Kao-ping River in the southwest of Taiwan and the Lake Sniardwy in northern Poland. Copepod intermediate hosts were infected with these L2 and infective L3 larvae were harvested. Eels were then infected via a stomach tube with 50 L3 larvae each.

Infected eels were kept in 160-liter tanks in groups of 20 individuals at a constant temperature of $22^{\circ} \mathrm{C}$ and a 12:12 photoperiod. The eels chosen for the experiment were $37.7 \mathrm{~cm} \pm 0.2( \pm \mathrm{SE})$ and $49.4 \mathrm{~cm} \pm 0.3$ long for the European and the Japanese eel, respectively. At 25, 50, 100 and 150 dpi 20 eels were dissected, resulting in total of 239 European and 216 Japanese eels. Eels that died during the trial were not considered in the statistical analysis. The tanks were continuously provided with oxygenated tap water and fed ad libitum with commercial fish pellets (Dan-Ex 2848, Dana Feed A/S Ltd, Horsens, Denmark). The experiment had been approved by the responsible authorities (Regierungspräsidium Karlsruhe).

At dissection, the swim bladder was opened, adult parasites were sexed and preserved in $70 \%$ ethanol. Body dimensions were measured at $0.65 \times, 2.0 \times$ or $5.0 \times$ magnification using a dissecting microscope (STEMI 2000, Carl Zeiss) equipped with a measuring ocular. Afterwards the anterior end of the worms was removed and covered with Berlese-mixture (Waldeck GmbH \& Co. KG, Division Chroma, 3D 101) on a glass slide. Dimensions of the oesophagus and buccal capsule were measured at $10 \times$ and $100 \times$ magnification under a compound microscope (Axiolab, Carl Zeiss) using a measuring ocular. In order to describe differences in the shape of the morphological features, the ratio of each measurement pair (length/width) was calculated.

\section{Statistics}

The models were performed separately for each term acting as response variable (the length, width and ratio of body, oesophagus and buccal capsule); the German parasite population in the European eel served as a 
Table 4 Set up of the mixed-effects linear models morphological dimensions of Anguillicola crassus: response and explanatory variables in the minimal adequate models after simplification

\begin{tabular}{|c|c|c|}
\hline Response variable & $\begin{array}{l}\text { Referenced } \\
\text { in text as }\end{array}$ & $\begin{array}{l}\text { Explanatory variables in the } \\
\text { minimal adequate models }\end{array}$ \\
\hline \multirow[t]{8}{*}{ Body length } & \multirow{8}{*}{$\begin{array}{l}\text { Additional file 1: } \\
\text { Table S1 }\end{array}$} & Eel species \\
\hline & & Dpi \\
\hline & & $\begin{array}{l}\text { Number of adults recovered } \\
\text { alive }\end{array}$ \\
\hline & & Number of $L 3$ recovered alive \\
\hline & & Worm sex \\
\hline & & Eel species*dpi \\
\hline & & Dpi*worm sex \\
\hline & & Eel species*worm sex \\
\hline \multirow[t]{8}{*}{ Body width } & \multirow{8}{*}{$\begin{array}{l}\text { Additional file 2: } \\
\text { Table S2 }\end{array}$} & Eel species \\
\hline & & Dpi \\
\hline & & $\begin{array}{l}\text { Number of adults recovered } \\
\text { alive }\end{array}$ \\
\hline & & Number of $L 3$ recovered alive \\
\hline & & Worm sex \\
\hline & & Eel species*dpi \\
\hline & & Dpi*worm sex \\
\hline & & Eel species*worm sex \\
\hline \multirow{8}{*}{$\begin{array}{l}\text { Ratio body } \\
\text { length/width }\end{array}$} & \multirow[t]{8}{*}{ Table 1} & Eel species \\
\hline & & Population \\
\hline & & Dpi \\
\hline & & Worm sex \\
\hline & & Eel species*population \\
\hline & & Eel species*dpi \\
\hline & & Dpi*worm sex \\
\hline & & Eel species*worm sex \\
\hline \multirow[t]{8}{*}{ Oesophagus length } & \multirow{8}{*}{$\begin{array}{l}\text { Additional file 4: } \\
\text { Table S3 }\end{array}$} & Eel species \\
\hline & & Population \\
\hline & & Dpi \\
\hline & & $\begin{array}{l}\text { Number of adults recovered } \\
\text { alive }\end{array}$ \\
\hline & & Number of $L 3$ recovered alive \\
\hline & & Worm sex \\
\hline & & Eel species*dpi \\
\hline & & Dpi*worm sex \\
\hline \multirow[t]{7}{*}{ Oesophagus width } & \multirow{7}{*}{$\begin{array}{l}\text { Additiolan file 5: } \\
\text { Table S4 }\end{array}$} & Eel species \\
\hline & & Population \\
\hline & & Dpi \\
\hline & & $\begin{array}{l}\text { Number of adults recovered } \\
\text { alive }\end{array}$ \\
\hline & & Worm sex \\
\hline & & Eel species*dpi \\
\hline & & Dpi*worm sex \\
\hline
\end{tabular}

Table 4 Set up of the mixed-effects linear models morphological dimensions of Anguillicola crassus: response and explanatory variables in the minimal adequate models after simplification (Continued)

\begin{tabular}{|c|c|c|}
\hline \multirow{5}{*}{$\begin{array}{l}\text { Ratio oesophagus } \\
\text { length/width }\end{array}$} & \multirow[t]{5}{*}{ Table 2} & Eel species \\
\hline & & Population \\
\hline & & Dpi \\
\hline & & Worm sex \\
\hline & & Eel species*dpi \\
\hline \multirow{7}{*}{$\begin{array}{l}\text { Buccal capsule } \\
\text { length }\end{array}$} & \multirow{7}{*}{$\begin{array}{l}\text { Additional file 7: } \\
\text { Table S5 }\end{array}$} & Eel species \\
\hline & & Population \\
\hline & & Dpi \\
\hline & & $\begin{array}{l}\text { Number of adults recovered } \\
\text { alive }\end{array}$ \\
\hline & & Number of $L 3$ recovered alive \\
\hline & & Worm sex \\
\hline & & Eel species*dpi \\
\hline \multirow{7}{*}{$\begin{array}{l}\text { Buccal capsule } \\
\text { width }\end{array}$} & \multirow{7}{*}{$\begin{array}{l}\text { Additional file 8: } \\
\text { Table S6 }\end{array}$} & Eel species \\
\hline & & Population \\
\hline & & Dpi \\
\hline & & Number of $L 3$ recovered alive \\
\hline & & Worm sex \\
\hline & & Eel species*dpi \\
\hline & & Population*dpi \\
\hline \multirow{5}{*}{$\begin{array}{l}\text { Ratio buccal capsule } \\
\text { length/width }\end{array}$} & \multirow{5}{*}{ Table 3} & Eel species \\
\hline & & Population \\
\hline & & Dpi \\
\hline & & Worm sex \\
\hline & & Eel species*worm sex \\
\hline
\end{tabular}

*Refers to the interactions between explanatory variables given in the table. For more information please see Methods.

reference group. As measurements of different worms from one eel are not statistically independent, mixedeffects linear models were chosen for statistical modeling. The models were fitted for response variables presented in Table 4. After exclusion of extreme outliers, models were fitted by stepwise simplification starting from maximal models including the following explanatory variables: eel species, length of eel, parasite population, dpi (as a continuous variable), eel specimen, worm sex, number of L3, L4 and adult worms. Additionally, all three-way interactions between eel species, parasite population and time in dpi and sex of the worms and dpi and sex of the worms and eel species were allowed.

As the number of observations at $25 \mathrm{dpi}$ was statistically insufficient, the starting time for all statistical models were set to $50 \mathrm{dpi}$. All count data were modeled as numerical variables. Eel specimen was modeled as a random effects explanatory variable, all other factors 
were modeled as fixed effects explanatory variables. Significant explanatory variables left after simplification are presented in Table 4. All statistics were executed in R (R Development Core Team, 2009) using the packages MASS [33] and lme4 [34]. Significance was assumed if $\mathrm{p}<0.05$.

\section{Additional files}

Additional file 1: Table S1. Minimal adequate mixed-effects linear model for body length of Anguillicola crassus; reference group: German parasite population in the European eel. Significant effects are in bold.

Additional file 2: Table S2. Minimal adequate mixed-effects linear model for body width of Anguillicola crassus; reference group: German parasite population in the European eel. Significant effects are in bold.

Additional file 3: Figure S1. Body length and body width of male adults of Anguillicola crassus in Anguilla anguilla and Anguilla japonica with the arithmetic mean values (horizontal and vertical lines) and the linear regression lines. 1 - German parasite population, 2 - Polish parasite population, 3 - Taiwanese parasite population. Dpi - days post infection.

Additional file 4: Table S3. Minimal adequate mixed-effects linear model for oesophagus width of Anguillicola crassus; reference group: German parasite population in the European eel. Significant effects are in bold).

Additional file 5: Table S4. Minimal adequate mixed-effects linear model for oesophagus length of Anguillicola crassus; reference group: German parasite population in the European eel. Significant effects are in bold.

Additional file 6: Figure S2. Oesophagus length and body width of male adults of Anquillicola crassus in Anquilla anquilla and Anquilla japonica with the arithmetic mean values (horizontal and vertical lines) and the linear regression lines. 1 - German parasite population, 2 - Polish parasite population, 3 - Taiwanese parasite population. Dpi - days post infection.

Additional file 7: Table S5. Minimal adequate mixed-effects linear model for buccal capsule length of Anguillicola crassus; reference group: German parasite population in the European eel. Significant effects are in bold.

Additional file 8: Table S6. Minimal adequate mixed-effects linear model for buccal capsule width of Anguillicola crassus; reference group: German parasite population in the European eel. Significant effects are in bold.

Additional file 9: Figure S3. Buccal capsule length and width of male adults of Anguillicola crassus in Anguilla anguilla and Anguilla japonica with the arithmetic mean values (horizontal and vertical lines) and the linear regression lines. 1 - German parasite population, 2 - Polish parasite population, 3 - Taiwanese parasite population. Dpi - days post infection.

\section{Abbreviation \\ Dpi: Days post infection}

\section{Competing interests}

The authors declare that they have no competing interests.

\section{Authors' contributions}

UW planned and conducted the experiments, collected results, made the preliminary statistical analyses and wrote the manuscript. HT designed and supervised the experiments, and participated in interpretation of the results. EGH made the figures and participated in the statistical analysis. TB and BK carried out the statistical evaluation. TP helped with the preliminary statistical analyses, participated in the interpretation of the results and helped writing the manuscript. YSH organized the acquisition of The Japanese eels and supervised their dissection. All authors read and approved the final manuscript.

\section{Acknowledgements}

We would like to thank Dr. Albert Keim for the taxonomic classification of the copepods used for harvesting of the infective L3 stage of the parasite.

\section{Author details}

'Department of Ecology and Parasitology, Zoological Institute, Karlsruhe Institute of Technology, Kornblumenstrasse 13, Karlsruhe, Germany. ${ }^{2}$ Department of Stochastics, Karlsruhe Institute of Technology, Kaiserstrasse 89, Karlsruhe, Germany. ${ }^{3}$ Institute of Fisheries Science, College of Life Science, National Taiwan University, Taipei, Taiwan.

Received: 7 April 2014 Accepted: 26 September 2014

Published online: 14 October 2014

\section{References}

1. Kuwahara A, Niimi A, Itagaki H: Studies of a nematode parasitic in the air bladder of the eel: 1. Description of Anguillicola crassa n. sp. (Philometridae, Anguillicolidae). Jpn J Parasitol 1974, 23:275-279.

2. Kirk RS: The impact of Anguillicola crassus on European eels. Fish Manag Ecol 2003, 10:385-394.

3. Taraschewski H: Hosts and parasites as aliens. J Helminthol 2006 , 80:99-128.

4. Sures B, Knopf K: Parasites as a threat to freshwater eels? Science 2004, 304:209-211.

5. Moravec F: Parasitic nematodes of freshwater fishes of Europe. Prague: Academia; 2013.

6. Sures B, Knopf K, Taraschewski H: Development of Anguillicola crassus (Dracunculoidea, Anguillicolidae) in experimentally infected Balearic congers Ariosoma balearicum (Anguilloidea, Congridae). Dis Aquat Org 1999, 39:75-78.

7. Münderle M, Taraschewski H, Klar B, Chang CW, Shiao JC, Shen KN, He JT, Lin SH, Tzeng WN: Occurrence of Anguillicola crassus (Nematoda: Dracunculoidea) in Japanese eels Anguilla japonica from a river and an aquaculture unit in SW Taiwan. Dis Aquat Org 2006, 71:101-108.

8. Knopf K, Mahnke M: Differences in susceptibility of the European eel (Anguilla anguilla) and the Japanese eel (Anguilla japonica) to the swimbladder nematode Anguillicola crassus. Parasitology 2004, 129:491-496.

9. Han Y-S, Chang Y-T, Taraschewski H, Chang S-L, Chen C-C, Tzeng W-N: The swimbladder parasite Anguillicola crassus in native Japanese eels and exotic American eels in Taiwan. Zool Stud 2008, 47:667-675.

10. Weclawski U, Heitlinger EG, Baust T, Klar B, Petney T, San Han Y, Taraschewski H: Evolutionary divergence of the swim bladder nematode Anguillicola crassus after colonization of a novel host, Anguilla anguilla. BMC Evol Biol 2013, 13:78.

11. Polzer $\mathrm{M}$, Taraschewski $\mathrm{H}$ : Identification and characterization of the proteolytic enzymes in the developmental stages of the eel pathogenic nematode Anguillicola crassus. Parasitol Res 1993, 79:24-27.

12. Bruňanská $M$, Fagerholm H-P, Moravec F: Structure of the pharynx in the adult nematode Anguillicoloides crassus (Nematoda: Rhabditida). J Parasitol 2007, 93:1017-1028.

13. Bruňanská M, Fagerholm H-P, Moravec F, Vasilková Z: Ultrastructure of the buccal capsule in the adult female Anguillicoloides crassus (Nematoda: Anguillicolidae). Helminthologia 2010, 47:170-178.

14. Andrássy I: Klasse Nematoda:(Ordnungen Monhysterida, Desmoscolecida, Araeolaimida, Chromadorida, Rhabditida). Stuttgart: Fischer Verlag; 1984

15. Moravec F, Taraschewski H: Revision of the genus Anguillicola Yamaguti, 1935 (Nematoda: Anguillicolidae) of the swimbladder of eels, including descriptions of two new species, A. novaezelandiae sp. n. and $A$. papernai sp. n. Folia Parasitol 1988, 35:125-146.

16. Moravec F: Dracunculoid and Anguillicoloid nematodes parasitic in vertebrates. Prague: Academia; 2006.

17. Laetsch DR, Heitlinger EG, Taraschewski H, Nadler SA, Blaxter ML: The phylogenetics of Anguillicolidae (Nematoda: Anguillicoloidea), swimbladder parasites of eels. BMC Evol Biol 2012, 12:60

18. Neumann W: Schwimmblasenparasit Anguillicola bei Aalen. Fischer Teichwirt 1985, 11:322

19. Taraschewski H, Moravec F, Lamah T, Anders K: Distribution and morphology of two helminths recently introduced into European eel populations: Anguillicola crassus (Nematoda, Dracunculoidea) and Paratenuisentis ambiguus (Acanthocephala, Tenuisentidae). Dis Aquat Org 1987, 3:167-176. 
20. Nielsen ME: Infection status of the swimbladder worm, Anguillicola crassus in silver stage European eel, Anguilla anguilla, from three different habitats in Danish waters. J Appl Ichthyol 1997, 13:195-196.

21. Knopf K, Lucius R: Vaccination of eels (Anguilla japonica and Anguilla anguilla) against Anguillicola crassus with irradiated L3. Parasitology 2008, 135:633-640.

22. Heitlinger EG, Laetsch DR, Weclawski U, Han Y-S, Taraschewski H: Massive encapsulation of larval Anguillicoloides crassus in the intestinal wall of Japanese eels. Parasit Vectors 2009, 2:48.

23. Fonderie $P$, Steel $H$, Moens $T$, Bert W: Experimental induction of intraspecific morphometric variability in a single population of Halicephalobus cf. gingivalis may surpass total interspecifc variability. Nematology 2013, 15:529-544.

24. Fagerholm HP: Intra-specific variability of the morphology in a single population of the seal parasite Contracaecum osculatum (Rudolphi) (Nematoda, Ascaridoidea), with a redescription of the species. Zool Scripta 1989, 18:33-41.

25. Inglis WG: Allometric growth in the Nematoda. Nature 1954, 173:957-957.

26. Maes GE, Pujolar JM, Hellemans B, Volckaert FA: Evidence for isolation by time in the European eel (Anguilla anguilla L.). Mol Ecol 2006, 15:2095-2107.

27. Wirth $T$, Bernatchez $L$ : Genetic evidence against panmixia in the European eel. Nature 2001, 409:1037-1040.

28. Reimer LW, Hildebrand A, Scharberth D, Walter U: Anguillicola crassus in the Baltic sea: field data supporting transmission in brackish waters. Dis Aquat Org 1994, 18:77-79.

29. Rolbiecki L, Rokicki J: Anguillicola crassus - an alien nematode species from the swim bladders of eel Anguilla anguilla in the Polish zone of the southern Baltic and in the waters of northern Poland. Oceanol Hydrobiol Stud 2005, 34:121-136.

30. Wielgoss S, Taraschewski H, Meyer A, Wirth T: Population structure of the parasitic nematode Anguillicola crassus, an invader of declining north Atlantic eel stocks. Mol Ecol 2008, 17:3478-3495.

31. Larson A: The comparison of morphological and molecular data in phylogenetic systematics. In Molecular Approaches to Ecology and Evolution. Edited by DeSalle DR, Schierwater DB. Basel: Birkhäuser Verlag; 1998:275-296.

32. Heitlinger $\mathrm{E}$, Bridgett $\mathrm{S}$, Montazam A, Taraschewski H, Blaxter M: The transcriptome of the invasive eel swimbladder nematode parasite Anguillicola crassus. BMC Genomics 2013, 14:87.

33. Venables WN, Ripley BD: Modern Applied Statistics with S. New York: Springer; 2002.

34. Bates D, Maechler M, Bolker B, Walker S: Ime4: Linear Mixed-Effects Models Using Eigen and S4. J Stat Software 2014, http://CRAN.R-project.org/ package $=$ Ime4.

doi:10.1186/s12983-014-0074-9

Cite this article as: Weclawski et al:: Rapid evolution of Anguillicola crassus in Europe: species diagnostic traits are plastic and evolutionarily labile. Frontiers in Zoology 2014 11:74.

\section{Submit your next manuscript to BioMed Central and take full advantage of:}

- Convenient online submission

- Thorough peer review

- No space constraints or color figure charges

- Immediate publication on acceptance

- Inclusion in PubMed, CAS, Scopus and Google Scholar

- Research which is freely available for redistribution 